\title{
Correction to: Introduction
}

\author{
Maarten van Gageldonk, László Munteán, \\ and Ali Shobeiri
}

\section{Correction to:}

M. van Gageldonk et al. (eds.), Animation and Memory, https://doi.org/10.1007/978-3-030-34888-5

This chapter was previously published non-open access. It has now been changed to open access under a CC BY 4.0 license and the copyright holder to "The Author(s)". The book has also been updated with the change. 